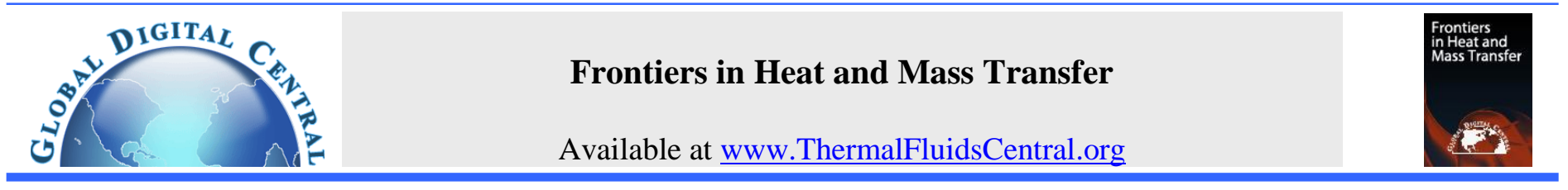

\title{
ASYMMETRIC FLOW OF A NANOFLUID BETWEEN EXPANDING OR CONTRACTING PERMEABLE WALLS WITH THERMAL RADIATION
}

\author{
A. Vijayalakshmi, S. Srinivas* \\ Department of Mathematics, School of Advanced Sciences, VIT University, Vellore- 632014, India
}

\begin{abstract}
In the present study, the flow and heat transfer characteristics of a nanofluid in an expanding or contracting porous channel with different permeabilities in presence of thermal radiation are investigated. Analytical solutions for the flow variables are obtained by employing homotopy analysis method (HAM). Maxwell-Garnetts and Brinkman models are considered to calculate the thermal conductivity and the viscosity of nanofluid. In this investigation, we considered water and ethylene glycol as base fluids and silver ( $\mathrm{Ag}$ ), $\operatorname{copper}(\mathrm{Cu})$, titanium dioxide ( $\left.\mathrm{TiO} \mathrm{O}_{2}\right)$ and alumina $\left(\mathrm{Al}_{2} \mathrm{O}_{3}\right)$ as nanoparticles. The effects of various emerging parameters on axial velocity, temperature, shear stress and Nusselt number distributions have been discussed. The results of present study are compared with the numerical solutions obtained by shooting technique along with Runge-Kutta fourth order scheme. We found that there is a good agreement between the analytical and the numerical solutions.

Keywords: Asymmetric flow, Nanofluid, Thermal radiation, Wall expansion ratio, Darcy number.
\end{abstract}

\section{INTRODUCTION}

Nanofluids are drawing a great deal of interest with their enormous potential to provide enhanced properties, particularly with respect to heat transfer. The studies pertaining to nanofluid flow have received a great attention of several researchers in view of its applications in industrial, biomedical, optical, electronic and thermal engineering (Madhesh and Kalaiselvam 2014; Mahian et al. 2012; Khanafer et al. 2003; Bachok et al. 2012(a); Hatami et al. 2013; Hatami and Ganji 2014; Rahimi-Gorji et al. 2015). The word nanofluid was first noticed by Choi(1995). Oztop and Abu-Nada (2008) studied numerically the natural convective heat transfer in a partially heated rectangular enclosure filled with nanofluids. In their study it was found that, different models for density and viscosity of nanoparticles were tested and there was an increase in mean Nusselt number with an increase of nanoparticles volume fraction. Vajravelu et al. (2011) analyzed the convective heat transfer of $\mathrm{Ag}$-water and $\mathrm{Cu}$-water nanofluids over a stretching surface using Keller-Box method. Hamad et al. (2011) discussed the magnetic field effects on free convection flow of a nanofluid past a vertical semi-infinite flat plate. The boundary layers of an unsteady stagnation point flow of a nanofluid were investigated by Bachok et al. (2012b). They obtained numerical solutions for three types of nanoparticles namely copper $(\mathrm{Cu})$, alumina $\left(\mathrm{Al}_{2} \mathrm{O}_{3}\right)$, and titanium dioxide $\left(\mathrm{TiO}_{2}\right)$ in the water based fluid. The effect of wall temperature on double diffusive natural convection of $\mathrm{Al}_{2} \mathrm{O}_{3}$-water nanofluid in an enclosure was numerically studied by Sheikhzadeh et al. (2013). The convective instability driven by buoyancy and heat transfer characteristics of nanofluids were investigated by Kim et al. (2004). The authors reported that the density and heat capacity of the nanoparticles increased the convective motion in a nanofluid. Domairry and Hatami (2014) examined the squeezing $\mathrm{Cu}$-water nanofluid flow analysis between parallel plates by DTM-Padé method. Dogonchi et al. (2015) studied the motion analysis of a spherical solid particle in plane Couette Newtonian fluid flow. Ahmadi et al. (2014) analyzed the unsteady flow and the related heat transfer of a nanofluid over an unsteady stretching flat plate. Ghasemi et al. (2015) studied about the blood flow containing nanoparticles through porous arteries in presence of magnetic field using analytical methods. Abu-Nada (2008) made a numerical investigation of heat transfer over a backward facing step using nanofluids. Malvandi and Ganji (2014) examined the laminar flow and convective heat transfer of water/alumina nanofluid inside a parallel-plate channel in the presence of a uniform magnetic field.

The study of thermal radiation has gained much attention of several researchers due to many applications in environmental and scientific processes, physics and engineering, for example, in aeronautics, fire research, heating and cooling of channels, nuclear power plants, gas turbines, and various propulsion devices for missiles, aircraft, space vehicles, and satellites (Brewster 1992; Srinivas et al. 2015; Hayat et al. 2011; Zheng et al. 2013; Nadeem and Haq 2015). Rad and Aghanajafi (2009) studied the thermal analysis of single phase laminar flow of nanofluid in a cooled rectangular microchannel subject to the heat sink and uniform wall temperature condition. Rahman and Eltayeb (2013) investigated numerically, the heat transfer characteristics of a two-dimensional steady hydromagnetic natural convection flow of nanofluids over a non-linear stretching sheet in the presence of radiation and convective boundary condition. Hady et al. (2012) analyzed the flow and heat transfer characteristics of a viscous nanofluid over a nonlinearly stretching sheet with thermal radiation and variable wall temperature. Hayat et al. (2015a) examined the radiation effects on MHD flow of Powell-Eyring nanofluid by a stretching cylinder. Haq et al. (2015) studied the problem of simultaneous effects of radiation and convective boundary condition on the two-dimensional boundary layer flow of natural convective micropolar nanofluid along a vertically stretching sheet. Zhang et al. (2015) studied the MHD flow and radiation heat transfer of nanofluids in porous media with variable heat flux and chemical reaction. Recently, Sheikholeslami et al. (2015) analyzed the effect of thermal radiation on magnetohydrodynamics of nanofluid flow between two horizontal rotating plates. 
The study of laminar flow between permeable deformable walls has received much attention due to wide range of applications in technological and biological flows. For example, the transport of biological fluids through expanding or contracting vessels, the synchronous pulsation of porous diaphragms, the modeling of air and blood circulation in the respiratory system, binary gas diffusion, filtration, ablation cooling, surface sublimation and the regression of the burning surface in solid rocket motors. Many investigations in this direction have been carried out by several researchers (Uchida and Aoki 1977; Dauenhauer and Majdalani 1999; Majdalani et al. 2002; Majdalani and Zhou 2003; Boutros et al. 2007; Dinarvand et al. 2009; Si et al. 2011a; Fakour et al. 2015). Si et al. (2011b) studied analytically the asymmetric laminar flow of micropolar fluid through porous channel with an expanding or contracting wall using homotopy analysis method (HAM). Xin-hui et al. (2011) analyzed the asymmetric laminar flow in a porous channel with expanding or contracting walls using HAM. Srinivas et al. (2012) studied analytically the effects of thermal-diffusion and diffusion-thermo on viscous fluid in a porous channel with slowly expanding or contracting walls. The influence of heat transfer and chemical reaction on asymmetric laminar flow between two slowly expanding or contracting walls has been investigated by Reddy et al. (2013) using a double perturbation in the permeation Reynolds and the wall expansion ratio. Srinivas et al. (2014) have analyzed the hydromagnetic flow of a nanofluid in a porous channel with expanding or contracting walls by using HAM. Nanofluid flow and heat transfer in an asymmetric porous channel with expanding or contracting wall was investigated by Hatami et al. (2014) using Galerkin and Least square methods. In this investigation, the authors have considered semi-porous channel with suction/injection at upper wall which expands or contracts at a time dependent rate and the lower one is impermeable and stationary.

The main focus of the present work is to study the influence of thermal radiation on asymmetric laminar flow of a nanofluid in an expanding and contracting porous channel with different permeabilities. We considered different base fluids (water and ethylene glycol) and nanoparticles such as copper ( $\mathrm{Cu}$ ), silver ( $\mathrm{Ag}$ ), alumina $\left(\mathrm{Al}_{2} \mathrm{O}_{3}\right)$, and titanium dioxide $\left(\mathrm{TiO}_{2}\right)$. The governing equations are transformed into ordinary differential equations using similarity transformations and then solved analytically using homotopy analysis method (HAM) developed by Liao $(2003,2014)$. The influence of various pertinent parameters on flow and heat transfer characteristics of nanofluid has been discussed.

\section{FORMULATION OF THE PROBLEM}

Consider the laminar, isothermal and incompressible flow of nanofluid between two permeable surfaces that enable the fluid to enter or exit during successive expansions or contractions. One side of the cross section representing the distance $2 a(t)$ between the walls, which is much smaller than the width and length of the channel. A planar section of the flow domain is shown in Fig. 1. Both the channel walls are assumed to have different permeabilities and expand or contract uniformly at a time-dependent rate $\dot{a}(t)$. The channel is assumed to be semi-infinite in length. Under these assumptions, the governing flow equations are given by

$$
\begin{aligned}
& \frac{\partial \hat{u}}{\partial \hat{x}}+\frac{\partial \hat{v}}{\partial \hat{y}}=0 \\
& \frac{\partial \hat{u}}{\partial t}+\hat{u} \frac{\partial \hat{u}}{\partial \hat{x}}+\hat{v} \frac{\partial \hat{v}}{\partial \hat{y}}=-\frac{1}{\rho_{n f}} \frac{\partial \hat{p}}{\partial \hat{x}}+\frac{\mu_{n f}}{\rho_{n f}}\left(\frac{\partial^{2} \hat{u}}{\partial \hat{x}^{2}}+\frac{\partial^{2} \hat{u}}{\partial \hat{y}^{2}}\right)-\frac{\mu_{n f} \Phi}{\rho_{n f} k} \hat{u} \\
& \frac{\partial \hat{v}}{\partial t}+\hat{u} \frac{\partial \hat{v}}{\partial \hat{x}}+\hat{v} \frac{\partial \hat{v}}{\partial \hat{y}}=-\frac{1}{\rho_{n f}} \frac{\partial \hat{p}}{\partial \hat{y}}+\frac{\mu_{n f}}{\rho_{n f}}\left(\frac{\partial^{2} \hat{v}}{\partial \hat{x}^{2}}+\frac{\partial^{2} \hat{v}}{\partial \hat{y}^{2}}\right)-\frac{\mu_{n f} \Phi}{\rho_{n f} k} \hat{v}
\end{aligned}
$$

$\frac{\partial T}{\partial t}+\hat{u} \frac{\partial T}{\partial \hat{x}}+\hat{v} \frac{\partial T}{\partial \hat{y}}=\frac{k_{n f}}{\left(\rho C_{p}\right)_{n f}}\left(\frac{\partial^{2} T}{\partial \hat{y}^{2}}\right)-\frac{1}{\left(\rho C_{p}\right)_{n f}} \frac{\partial q_{r}}{\partial \hat{y}}$

where $\hat{u}, \hat{v}$ are the velocity components along $\hat{x}$ and $\hat{y}$ directions respectively, $t$ is time, $\hat{p}$ is the dimensional pressure, $\Phi$ and $k$ are the porosity and permeability of porous medium, $T$ is the temperature, $\rho_{n f}$ is the effective density of the nanofluid, $\mu_{n f}$ is the effective dynamic viscosity of the nanofluid, $\left(\rho C_{p}\right)_{n f}$ is the heat capacitance of the nanofluid, $k_{n f}$ is the thermal conductivity of the nanofluid.

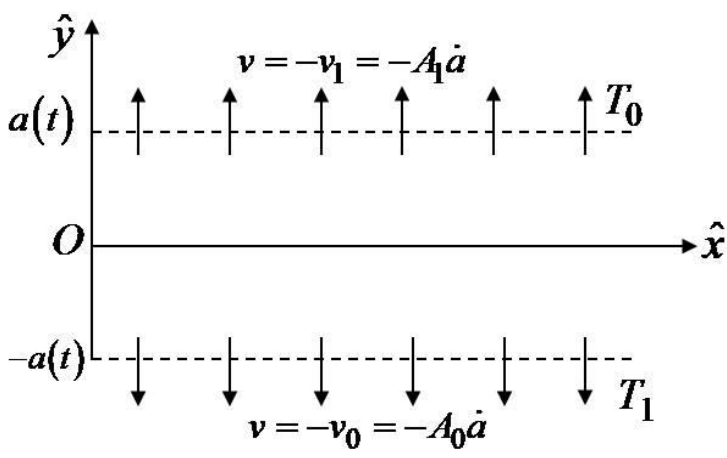

Fig. 1 Two dimensional domain with expanding or contracting porous walls.

The corresponding boundary conditions are

$\hat{u}=0 ; \hat{v}=-v_{0}=-A_{0} \dot{a}, T=T_{1}$, at $\hat{y}=-a(t)$

$\hat{u}=0 ; \hat{v}=-v_{1}=-A_{1} \dot{a}, T=T_{0}$, at $\hat{y}=a(t)$

where $A_{0}=v_{0} / \dot{a}$ and $A_{1}=v_{1} / \dot{a}$ are the measure of wall permeabilities, $T_{0}, T_{1}\left(>T_{0}\right)$ are the temperatures of the upper and lower walls, respectively.

The physical properties of nanofluid such as $\rho_{n f}, \mu_{n f},\left(\rho C_{p}\right)_{n f}$ and $k_{n f}$ are given as (Khanafer et al. 2003; Abu-Nada 2008; Zhang et al. 2015; Hatami et al. 2014)

$$
\begin{aligned}
& \mu_{n f}=\frac{\mu_{f}}{(1-\phi)^{2.5}} \\
& \rho_{n f}=(1-\phi) \rho_{f}+\phi \rho_{s} \\
& \left(\rho C_{p}\right)_{n f}=(1-\phi)\left(\rho C_{p}\right)_{f}+\phi\left(\rho C_{p}\right)_{s} \\
& \frac{k_{n f}}{k_{f}}=\frac{k s+2 k_{f}-2 \phi\left(k_{f}-k_{s}\right)}{k s+2 k_{f}+\phi\left(k_{f}-k_{s}\right)}
\end{aligned}
$$

where $\rho_{f}$ is the density of the base fluid, $\rho_{s}$ is density of the nanoparticle, $\mu_{f}$ is viscosity of the base fluid, $\phi$ is the volume fraction of nanoparticles, $\left(\rho C_{p}\right)_{f},\left(\rho C_{p}\right)_{s}$ are the heat capacitance of the base fluid and nanoparticles respectively and $k_{f}, k_{s}$ are thermal conductivities of base fluid and nanoparticle respectively. The thermophysical properties of different base fluids and nanoparticles are shown Table 1.

Introducing the stream function and mean flow velocity by putting

$\hat{u}=\frac{\partial \hat{\psi}}{\partial \hat{y}} ; \hat{v}=-\frac{\partial \hat{\psi}}{\partial \hat{x}}$.

Due to mass conservation, a similar solution with respect to $\hat{x}$ can be assumed to be of the form

$\hat{\psi}=v \hat{x} \hat{F}(\eta, t) / a, \hat{u}=v \hat{x} a^{-2} \hat{F}_{\eta}(\eta, t), \hat{v}=-v a^{-1} \hat{F}(\eta, t)$ 
where $\eta=\hat{y} / a, \hat{F}_{\eta}=\frac{\partial \hat{F}}{\partial \eta}$.

Table 1 Thermophysical properties of base fluids and nanoparticles (Madhesh 2014; Ozotop and Abu-Nada 2008; Ahmadi et al. 2014; Zhang et al. 2015).

\begin{tabular}{|c|c|c|c|c|c|c|}
\hline \multirow{2}{*}{$\begin{array}{c}\text { Physical } \\
\text { Properties }\end{array}$} & \multicolumn{3}{|c|}{ Base fluid } & \multicolumn{4}{|c|}{ Nanoparticle } \\
\cline { 2 - 7 } & Water & $\begin{array}{c}\text { Ethylene } \\
\text { Glycol } \\
(E G)\end{array}$ & $\mathrm{Al}_{2} \mathrm{O}_{3}$ & $\mathrm{Ag}$ & $\mathrm{Cu}$ & $\mathrm{TiO}_{2}$ \\
\hline$\rho\left(\mathrm{kg} / \mathrm{m}^{3}\right)$ & 997.1 & 1087 & 3970 & 10500 & 8933 & 4250 \\
\hline $\begin{array}{c}C_{p}(\mathrm{~J} / \mathrm{kg} \\
\mathrm{K})\end{array}$ & 4179 & 2562 & 765 & 235 & 385 & 686.2 \\
\hline$\kappa(\mathrm{W} / \mathrm{m} \mathrm{K})$ & 0.613 & 0.2594 & 40 & 429 & 400 & 8.9538 \\
\hline
\end{tabular}

Now eliminating pressure from Eqs. (2)-(3) and then using the transformations given in Eq. (12) and following Uchida and Aoki 1977; Dauenhauer and Majdalani 1999; Majdalani and Zhou 2003; Xinhui et al. 2011, one obtains

$$
\begin{aligned}
& f^{i v}+\alpha \phi_{1}\left[\eta f^{\prime \prime \prime}+3 f^{\prime \prime}\right]+\phi_{1} R f f^{\prime \prime \prime}-\phi_{1} R f^{\prime \prime \prime}-\frac{1}{D a} f^{\prime \prime}=0 \\
& f(-1)=A, f^{\prime}(-1)=0, f^{\prime}(1)=0, f(1)=1
\end{aligned}
$$

where $\alpha(t)=a \dot{a} / v$ is the non-dimensional wall dilation rate and is defined positive for expansion and negative for contraction, $R=a v_{1} / v$ is the permeation Reynolds number which is positive for injection and negative for suction, $D a=\frac{k}{\Phi a^{2}}$ is the Darcy number, $A=\frac{v_{0}}{v_{1}}$, $\phi_{1}=\frac{\mu_{f}}{\mu_{n f}} \cdot \frac{\rho_{n f}}{\rho_{f}}$ and prime denotes the differentiation with respect to $\eta$.

By using the Rosseland approximation for radiation, the radiative heat flux is simplified as (Brewster 1992; Srinivas et al. 2015; Hayat et al. 2011; Zheng et al. 2013; Nadeem et al. 2015),

$q_{r}=-\frac{4 \sigma^{*}}{3 \kappa^{*}} \frac{\partial T^{4}}{\partial y}$

where $\sigma^{*}$ is the Stefan-Boltzmann constant and $\kappa^{*}$ is the mean absorption coefficient. We assumed that the temperature differences within the flow are sufficiently small such that the term $T^{4}$ may be expressed as a linear function of temperature. This is accomplished by expanding $T^{4}$ in a Taylor series about $T_{0}$ and neglecting higher order terms, thus

$$
T^{4} \cong 4 T_{0}^{3} T-3 T_{0}^{4} \text {. }
$$

The temperature of the nanofluid in channel can be expressed as

$$
T=T_{0}+B\left(\frac{\hat{x}}{a}\right)^{m_{1}} \theta(\eta)
$$

where $B$ is the constant of the fluid and $m_{1}$ is the power law index of the temperature. The dimensionless form of temperature from Eq. (17) is

$\theta=\frac{T-T_{0}}{T_{1}-T_{0}}$.

Substituting Eqs. (15)-(17) in Eq. (4), we get (Hayat et al. 2015b; Paul and Mandal 2014; Zhang et al. 2015)

$\left[\frac{\phi_{2}}{\phi_{3}}+\frac{4}{3} \frac{R d}{\phi_{3}}\right] \frac{1}{\operatorname{Pr}} \theta^{\prime \prime}+\alpha\left(\eta \theta^{\prime}+m_{1} \theta\right)-m_{1} R f^{\prime} \theta+R f \theta^{\prime}=0$ where $\phi_{2}=\frac{k_{n f}}{k_{f}}, \quad \phi_{3}=\frac{\left(\rho C_{P}\right)_{n f}}{\left(\rho C_{P}\right)_{f}}, R d=\frac{4 \sigma^{*} T_{0}^{3}}{\kappa^{*} k_{f}}$ is thermal radiation parameter, $\operatorname{Pr}=\frac{\mu_{f}\left(C_{p}\right)_{f}}{k_{f}}$ is the Prandtl number.

The corresponding boundary conditions are $\theta(-1)=1, \theta(1)=0$.

\section{SOLUTION OF THE PROBLEM}

Here we employed homotopy analysis method to obtain the analytical solutions for the system of equations (13) and (19) with the corresponding boundary conditions Eq. (14) and Eq. (20). The initial guesses $f_{0}, \theta_{0}$ and the auxiliary linear operators $L_{1}, L_{2}$ are given by

$$
\begin{aligned}
& f_{0}(\eta)=\frac{A-1}{4} \eta^{3}+\frac{3-3 A}{4} \eta+\frac{A+1}{2}, \theta_{0}(\eta)=\frac{1-\eta}{2} \\
& L_{1}(f)=\frac{d^{4} f}{d \eta^{4}}, L_{2}(\theta)=\frac{d^{2} \theta}{d \eta^{2}} \\
& \text { with } L_{1}\left(c_{1} \eta^{3}+c_{2} \eta^{2}+c_{3} \eta+c_{4}\right)=0, L_{2}\left(c_{5} \eta+c_{6}\right)=0,
\end{aligned}
$$

where $c_{i}(i=1,2,3,4,5,6)$ are constants. For further details of HAM, we refer the reader (Hatami et al. 2013; Srinivas et al. 2015; Hayat et al. 2011; Si et al. 2011a; Srinivas et al. 2014; Liao 2014).

\subsection{Convergence of the HAM solution}

The convergence of the series solutions and rate of convergence for the HAM depend upon the convergence-control parameter $h$. If $h$ is properly chosen, the homotopy series solution may converge rapidly. Hence to compute the range of admissible values of $h$ for $f(\eta)$ and $\theta(\eta)$, the $h$-curves are plotted in Fig. 2.
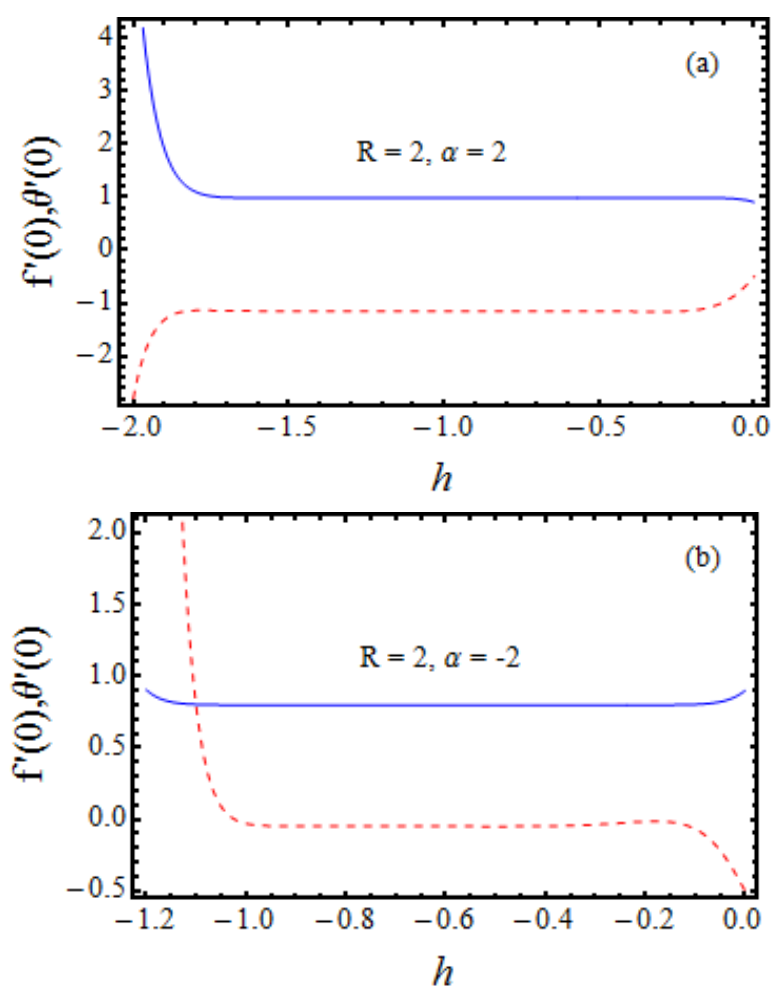

Fig. 2 h-curves for $20^{\text {th }}$ order approximation for $f(\eta), \theta(\eta)$ when $A=-0.2, \operatorname{Pr}=6.2, m_{1}=R d=1, D a=0.5$ for $\mathrm{Al}_{2} \mathrm{O}_{3}$-water nanofluid. 
The range of admissible values of $h$ is $-1.0 \leq h \leq-0.17$. Further, we define the square residual error to find the optimal value of $h$ by substituting the approximate solutions of $f(\eta), \theta(\eta)$ obtained by HAM into Eqs. (13) and (19) yields the residual error as follows:

$$
\begin{aligned}
& E_{1}=f^{i v}+\alpha \phi_{1}\left[\eta f^{\prime \prime \prime}+3 f^{\prime \prime}\right]+\phi_{1} R f f^{\prime \prime \prime}-\phi_{1} R f f^{\prime \prime}-\frac{1}{D a} f^{\prime \prime} \\
& E_{2}=\left[\frac{\phi_{2}}{\phi_{3}}+\frac{4}{3} \frac{R d}{\phi_{3}}\right] \frac{1}{\operatorname{Pr}} \theta^{\prime \prime}+\alpha\left(\eta \theta^{\prime}+m_{1} \theta\right)-m_{1} R f^{\prime} \theta+R f \theta^{\prime}
\end{aligned}
$$

where $E_{1}, E_{2}$ correspond to the residual error for $f(\eta), \theta(\eta)$, respectively. The square residual errors for $f(\eta), \theta(\eta)$ and the averaged square residual error are defined respectively as follows:

$\Delta_{i}=\int_{-1}^{1} E_{i}^{2} d \eta, \quad \Delta=\frac{1}{2} \sum_{i=1}^{2} \Delta_{i} \quad($ where $i=1,2)$.

The square residual error(SRE) for $f(\eta), \theta(\eta)$ and the averaged square residual error $(\Delta)$ are evaluated by varying the convergence control parameter $h$ to obtain the optimal value of $h$ which leads to minimum $\Delta$ which is given in Table 2. To the best of authors' knowledge there is no experimental work that measures the velocity, temperature, shear stress and Nusselt number profiles in an expanding or contracting porous channel. For the validity of our model, we compare the analytical solutions obtained by HAM with the numerical results obtained by shooting method coupled with Runge-Kutta scheme which are given in Fig. 3 and Table 3.

Table $220^{\text {th }}$ order approximation for the optimal convergencecontrol parameter $h$ and corresponding square residual error(SRE) for $\mathrm{Al}_{2} \mathrm{O}_{3}$-water nanofluid when $R=2, \alpha=2$,

\begin{tabular}{|c|c|c|c|}
\hline$h$ & SRE of $f$ & SRE of $\theta$ & $\begin{array}{c}\text { Averaged } \\
\operatorname{SRE}(\Delta)\end{array}$ \\
\hline-0.30 & $2.11637 \times 10^{-4}$ & $2.50601 \times 10^{-2}$ & $1.26359 \times 10^{-2}$ \\
\hline-0.35 & $1.69871 \times 10^{-5}$ & $1.14468 \times 10^{-2}$ & $5.73188 \times 10^{-3}$ \\
\hline-0.40 & $1.62331 \times 10^{-6}$ & $4.57970 \times 10^{-3}$ & $2.29066 \times 10^{-3}$ \\
\hline-0.45 & $1.05584 \times 10^{-7}$ & $1.86591 \times 10^{-3}$ & $9.33009 \times 10^{-4}$ \\
\hline-0.50 & $7.82159 \times 10^{-9}$ & $8.72966 \times 10^{-4}$ & $4.36237 \times 10^{-4}$ \\
\hline-0.55 & $6.03123 \times 10^{-10}$ & $3.93657 \times 10^{-4}$ & $1.96829 \times 10^{-4}$ \\
\hline-0.60 & $4.74049 \times 10^{-11}$ & $1.46178 \times 10^{-4}$ & $7.30888 \times 10^{-5}$ \\
\hline-0.65 & $4.56853 \times 10^{-12}$ & $5.59145 \times 10^{-5}$ & $2.79573 \times 10^{-5}$ \\
\hline-0.70 & $8.11867 \times 10^{-13}$ & $3.01164 \times 10^{-5}$ & $1.50582 \times 10^{-5}$ \\
\hline-0.75 & $1.36611 \times 10^{-13}$ & $1.43277 \times 10^{-5}$ & $7.16383 \times 10^{-6}$ \\
\hline-0.80 & $4.03542 \times 10^{-14}$ & $4.26913 \times 10^{-6}$ & $2.13257 \times 10^{-6}$ \\
\hline-0.85 & $2.60743 \times 10^{-14}$ & $2.09653 \times 10^{-6}$ & $1.04826 \times 10^{-6}$ \\
\hline-0.90 & $2.57262 \times 10^{-14}$ & $1.83675 \times 10^{-6}$ & $9.18373 \times 10^{-7}$ \\
\hline-0.95 & $3.85902 \times 10^{-14}$ & $7.32691 \times 10^{-7}$ & $3.66345 \times 10^{-7}$ \\
\hline-1.00 & $8.91263 \times 10^{-14}$ & $4.82851 \times 10^{-7}$ & $2.41426 \times 10^{-7}$ \\
\hline-1.05 & $4.04962 \times 10^{-13}$ & $7.91773 \times 10^{-7}$ & $3.95887 \times 10^{-6}$ \\
\hline-1.10 & $2.38480 \times 10^{-12}$ & $4.96720 \times 10^{-7}$ & $2.48361 \times 10^{-7}$ \\
\hline-1.15 & $1.42806 \times 10^{-11}$ & $5.77748 \times 10^{-7}$ & $2.88881 \times 10^{-7}$ \\
\hline-1.20 & $1.45439 \times 10^{-10}$ & $1.22724 \times 10^{-6}$ & $6.13693 \times 10^{-7}$ \\
\hline-1.25 & $4.52454 \times 10^{-9}$ & $1.06411 \times 10^{-6}$ & $5.34319 \times 10^{-7}$ \\
\hline-1.30 & $1.51238 \times 10^{-7}$ & $1.61609 \times 10^{-6}$ & $8.83662 \times 10^{-7}$ \\
\hline
\end{tabular}
$\operatorname{Pr}=6.2, m_{1}=R d=1, \phi=0.05, A=-0.2, D a=0.5$.
It was found that there is a good agreement between analytical and numerical solutions. Further, the dimensionless shear stress at the walls is defined as

$$
\tau=\frac{x}{(1-\phi)^{2.5} R}\left(f^{\prime \prime}(\eta)\right)_{\eta=-1,1} .
$$

and the heat transfer rate at the walls in terms of non-dimensional Nusselt number is defined as (Hatami et al. 2014)

$$
N u=-\frac{k_{n f}}{k_{f}} \frac{\partial T}{\partial \eta} /\left(T_{1}-T_{0}\right)=-\phi_{2} \theta^{\prime}(\eta)_{\eta=-1,1} .
$$
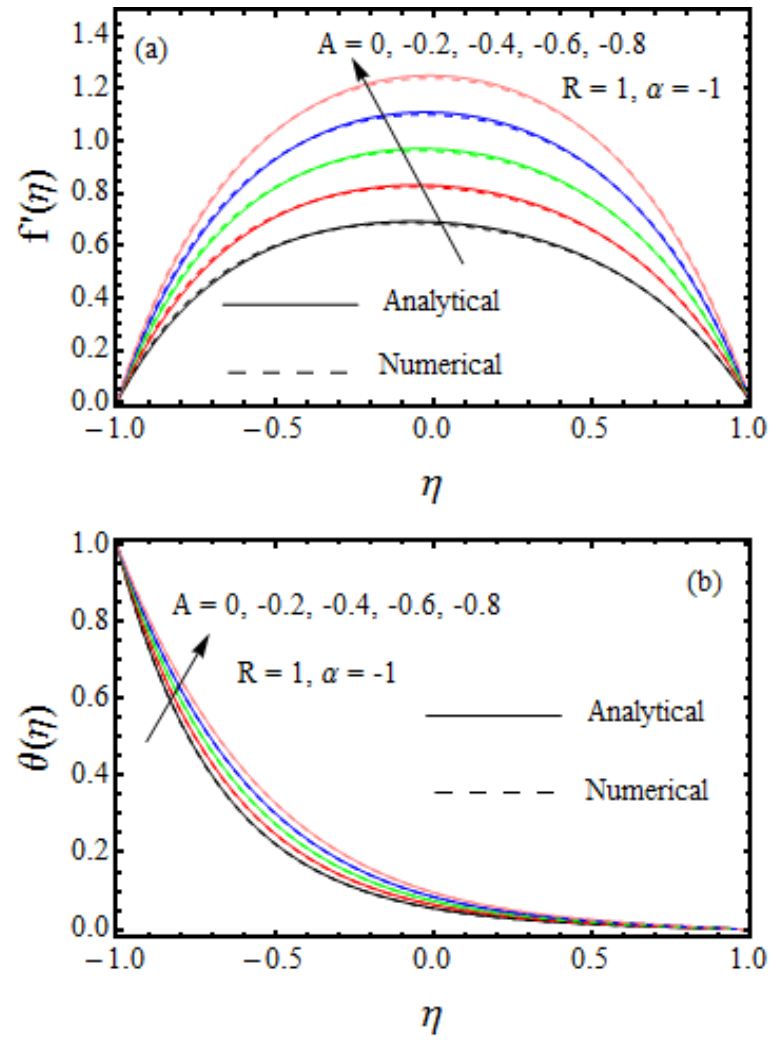

Fig. 3 Comparison between analytical and numerical solutions for $f^{\prime}(\eta)$ and $\theta(\eta)$ for $\mathrm{Al}_{2} \mathrm{O}_{3}$-water nanofluid.

Table 3 Comparison between analytical and numerical results for $\mathrm{Al}_{2} \mathrm{O}_{3}$-water nanofluid when $R=1, \alpha=-1, D a=0.5$, $\operatorname{Pr}=6.2, m_{1}=1, R d=1$.

\begin{tabular}{|c|c|c|c|c|}
\hline \multirow{2}{*}{$\eta$} & \multicolumn{2}{|c|}{$f(\eta)$} & \multicolumn{2}{c|}{$\theta(\eta)$} \\
\cline { 2 - 5 } & HAM & Numerical & HAM & Numerical \\
\hline 0.00 & 0.000000 & 0.000000 & 0.1075862 & 0.1073223 \\
\hline 0.10 & 0.138795 & 0.137694 & 0.0834474 & 0.0832697 \\
\hline 0.20 & 0.275810 & 0.273723 & 0.0644243 & 0.0643041 \\
\hline 0.30 & 0.409155 & 0.406308 & 0.0494652 & 0.0493809 \\
\hline 0.40 & 0.536723 & 0.533434 & 0.0376847 & 0.0376217 \\
\hline 0.50 & 0.656061 & 0.652713 & 0.0283426 & 0.0282925 \\
\hline 0.60 & 0.764236 & 0.761234 & 0.0208238 & 0.0207829 \\
\hline 0.70 & 0.857674 & 0.855381 & 0.0146182 & 0.0145861 \\
\hline 0.80 & 0.931970 & 0.930619 & 0.0093033 & 0.0092810 \\
\hline 0.90 & 0.981669 & 0.981229 & 0.0045281 & 0.0045169 \\
\hline 1.00 & 1.000000 & 1.000000 & 0.0000000 & 0.0000000 \\
\hline
\end{tabular}

\section{RESULTS AND DISCUSSION}

In this section, the graphical results are presented to understand the effects of different pertinent parameters on velocity, temperature, shear 
stress and Nusselt number distributions. To understand the physics of the problem, $\operatorname{Pr}=6.2, \quad m_{1}=R d=1, \quad D a=0.5, \quad \phi=0.05$ and $A=-0.2$ are chosen, unless otherwise stated. Here the flow is asymmetric because the permeability of walls is different. The effects of permeation Reynolds number $R$, the wall expansion ratio $\alpha, A$ and the Darcy number $D a$ on axial velocity $f^{\prime}(\eta)$ are shown in Figs. 4-7 for $\mathrm{Al}_{2} \mathrm{O}_{3}$-water nanofluid. Fig. 4 shows the influence of permeation Reynolds number on axial velocity for $\alpha=2,-2$. The axial velocity profiles are asymmetric and the maximum axial velocity lies between the center of the channel and the walls. For constant $\alpha$, for the case of injection, increasing injection leads to maximum velocity lies between the center and the lower wall while it lies between center and upper wall for the case of suction. Increasing $|R|$, the axial velocity profiles become more asymmetric. The variation of axial velocity for different values of wall expansion ratio is shown in Fig. 5 for $R=5,-5$. For every level of suction or injection the maximum axial velocity is near the center and minimum is near the walls. For the case of expanding walls $(\alpha>0)$, the maximum of axial velocity become higher near the center while it is lower for the case of contracting walls $(\alpha<0)$. Fig. 6 depicts the effect of $A$ on the axial velocity distribution. The axial velocity increases with increasing the magnitude of $A$ and the profile tends to symmetric near the center as $A$ varies from 0 to -1 . The maximum of axial velocity increases with increasing $|A|$. Fig.7 demonstrates the effect of $D a$ on axial velocity for $R=5, \alpha=2,-2$. It is observed that the axial velocity decreases near the walls with an increase in $D a$ while it increases near the center.
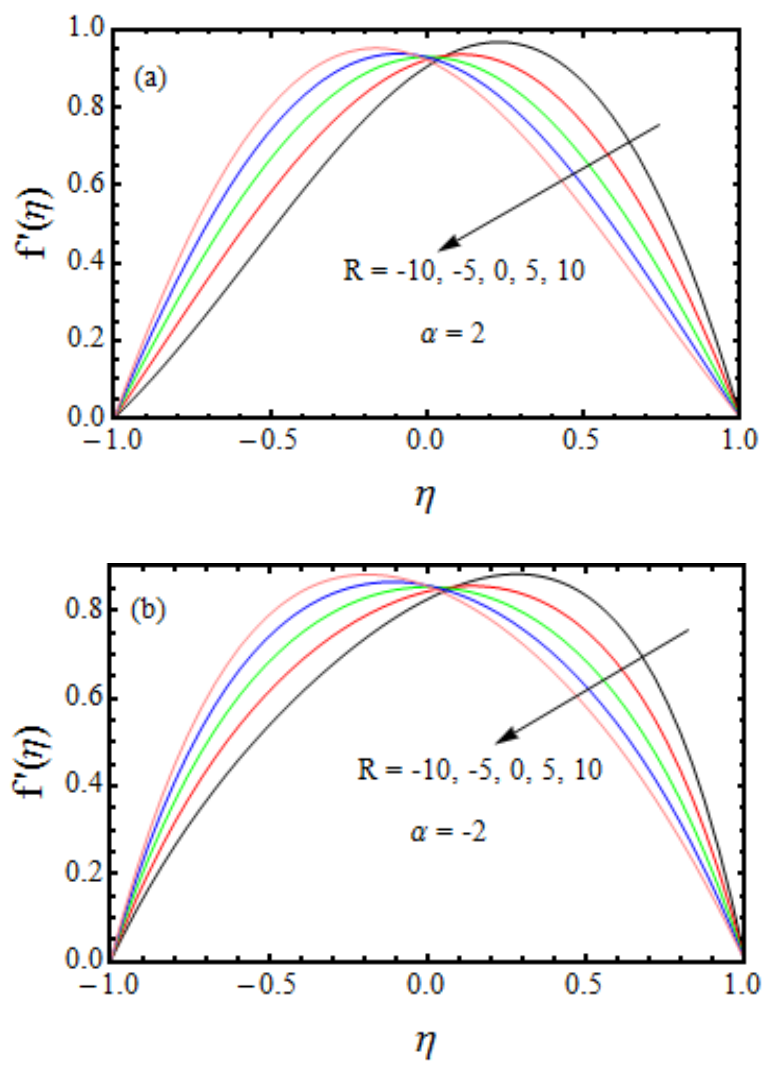

Fig. 4 Effect of $R$ on axial velocity distribution for $\mathrm{Al}_{2} \mathrm{O}_{3}$ - water nanofluid.
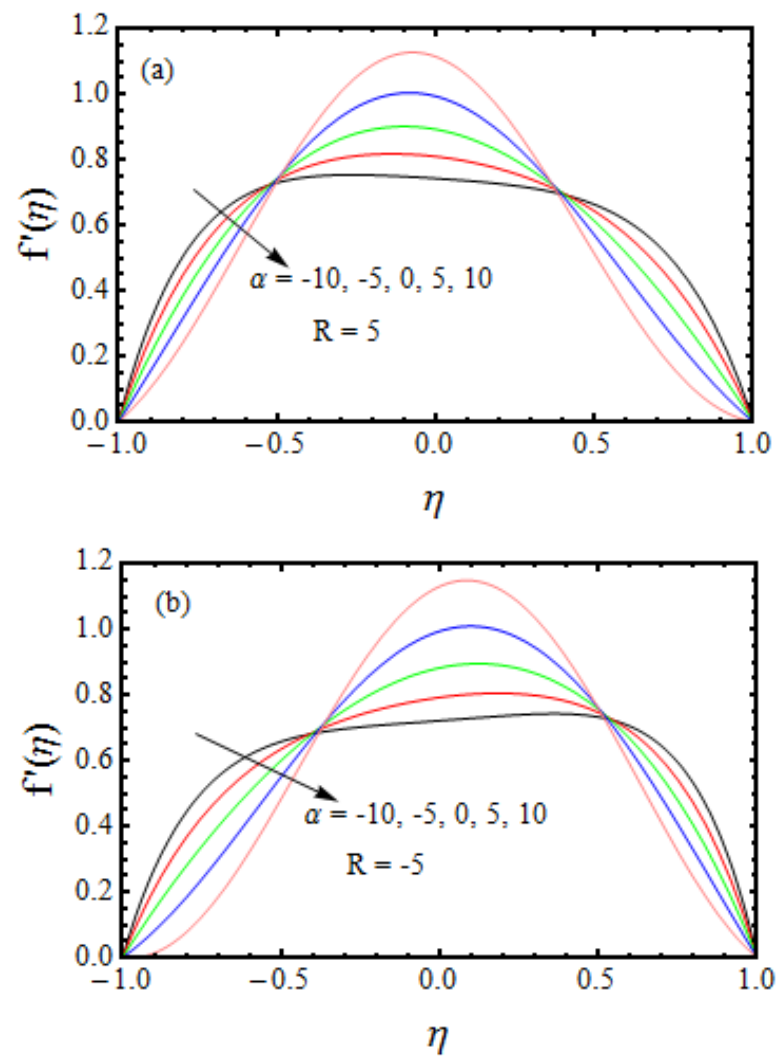

Fig. 5 Effect of $\alpha$ on axial velocity distribution for $\mathrm{Al}_{2} \mathrm{O}_{3}$-water nanofluid.
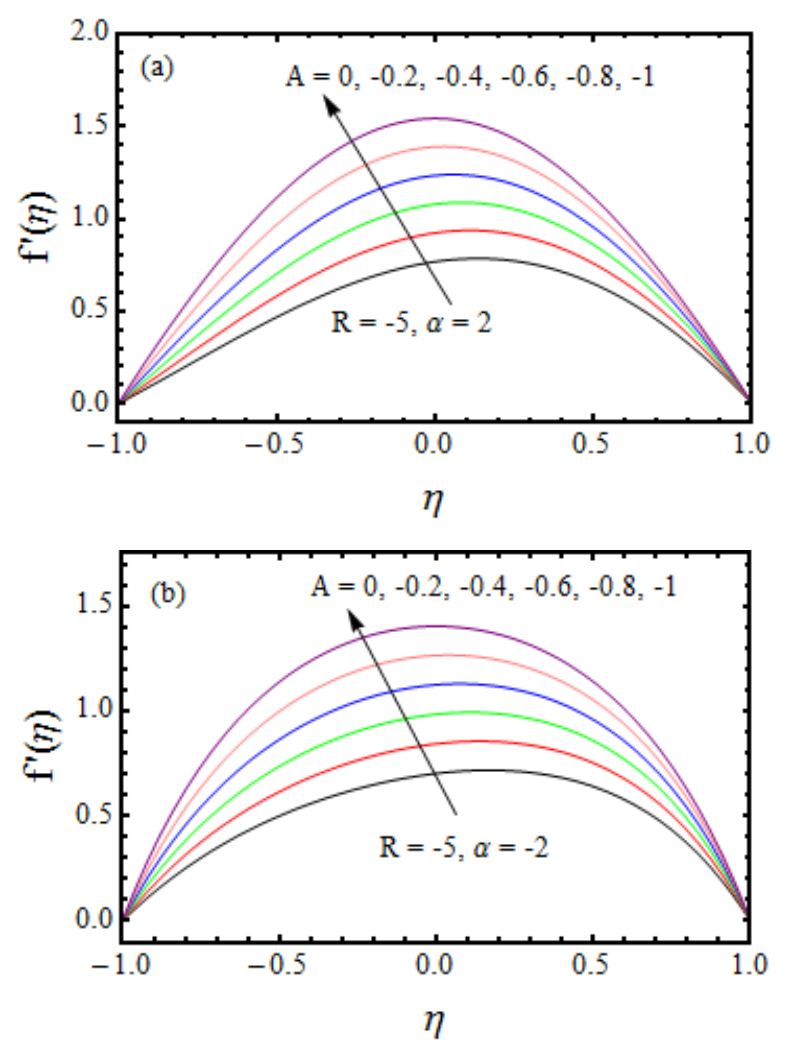

Fig. 6 Effect of $A$ on axial velocity distribution for $\mathrm{Al}_{2} \mathrm{O}_{3}$-water nanofluid. 

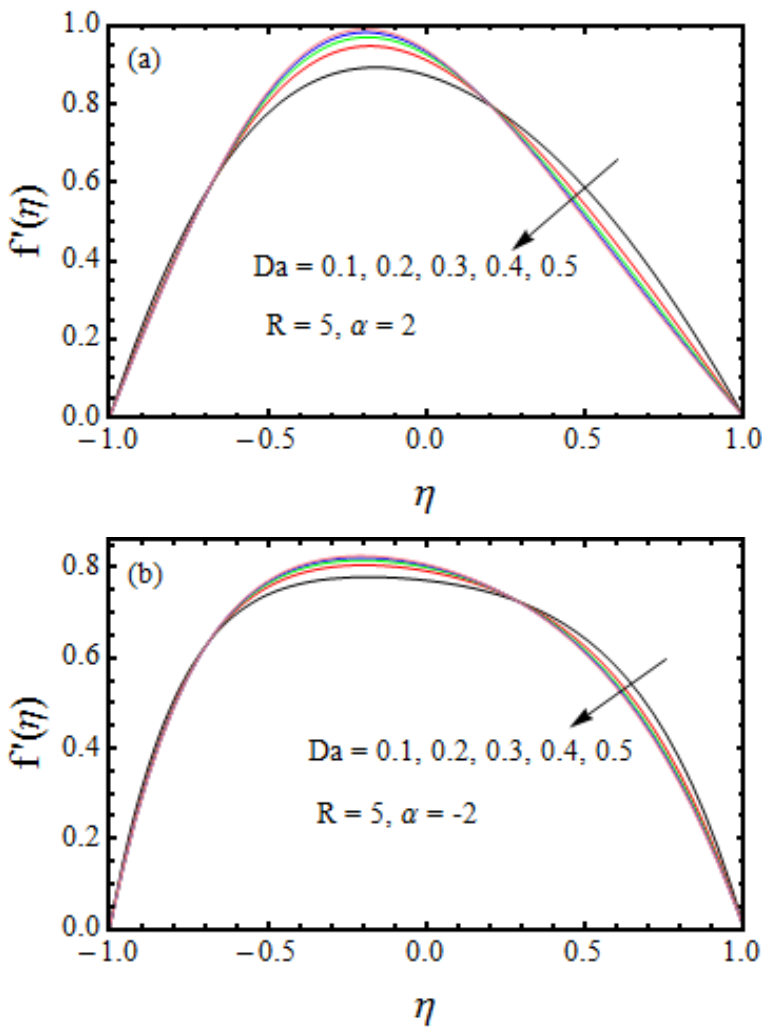

Fig. 7 Effect of $D a$ on axial velocity distribution for $\mathrm{Al}_{2} \mathrm{O}_{3}$-water nanofluid.
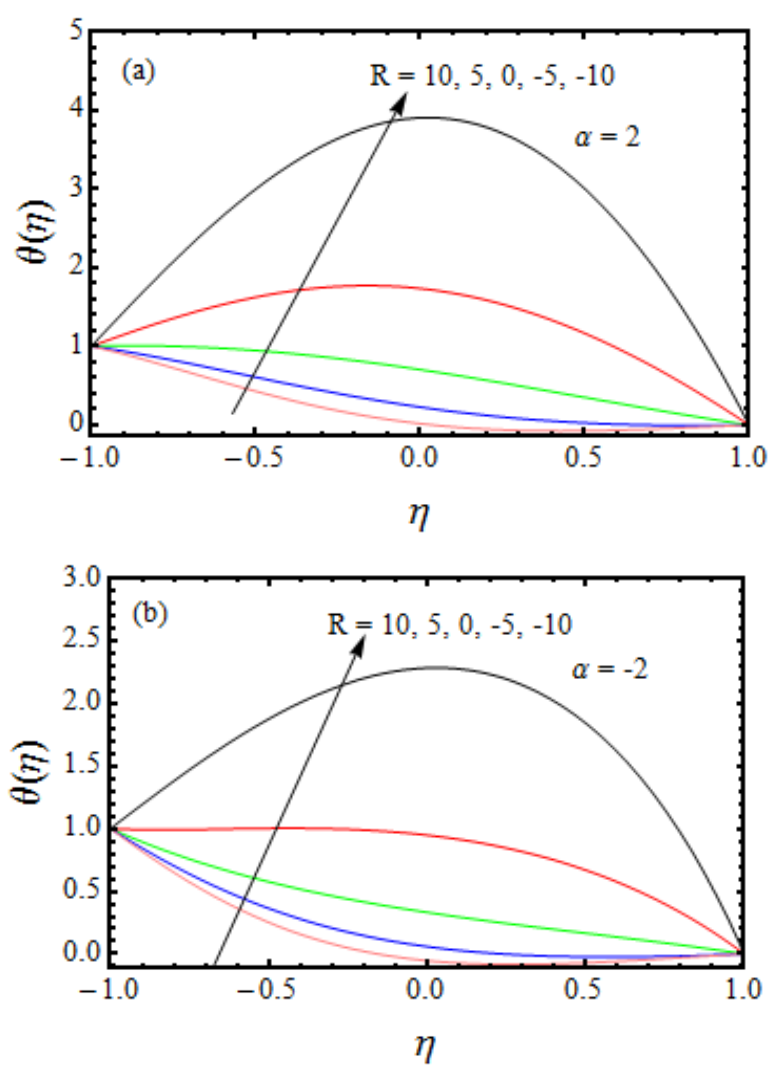

Fig. 8 Effect of $R$ on temperature distribution for $\mathrm{Al}_{2} \mathrm{O}_{3}$-water nanofluid.
The effects of $R, \alpha, m_{1}$ on temperature distribution $\theta$ are shown in Figs. 8-10 for $\mathrm{Al}_{2} \mathrm{O}_{3}$-water nanofluid. Fig. 8 illustrates the effect of permeation Reynolds number on $\theta$. For constant $\alpha$, increasing injection leads to lower temperature while increasing suction leads to higher temperature distribution. Fig. 9 demonstrates the variation of temperature distribution for different values of $\alpha$. It is observed that for every level of suction or injection, for the case of expanding walls, increasing $\alpha$ enhances the temperature. For the case of contracting walls, increasing $|\alpha|$ decreases the temperature. The influence of index parameter $m_{1}$ on $\theta$ is shown in Fig. 10 for $\alpha=2$, $R=5,-5$. For the case of injection combined with wall expansion the temperature decreases with increasing $m_{1}$ while it increases for the case of suction combined with wall expansion.
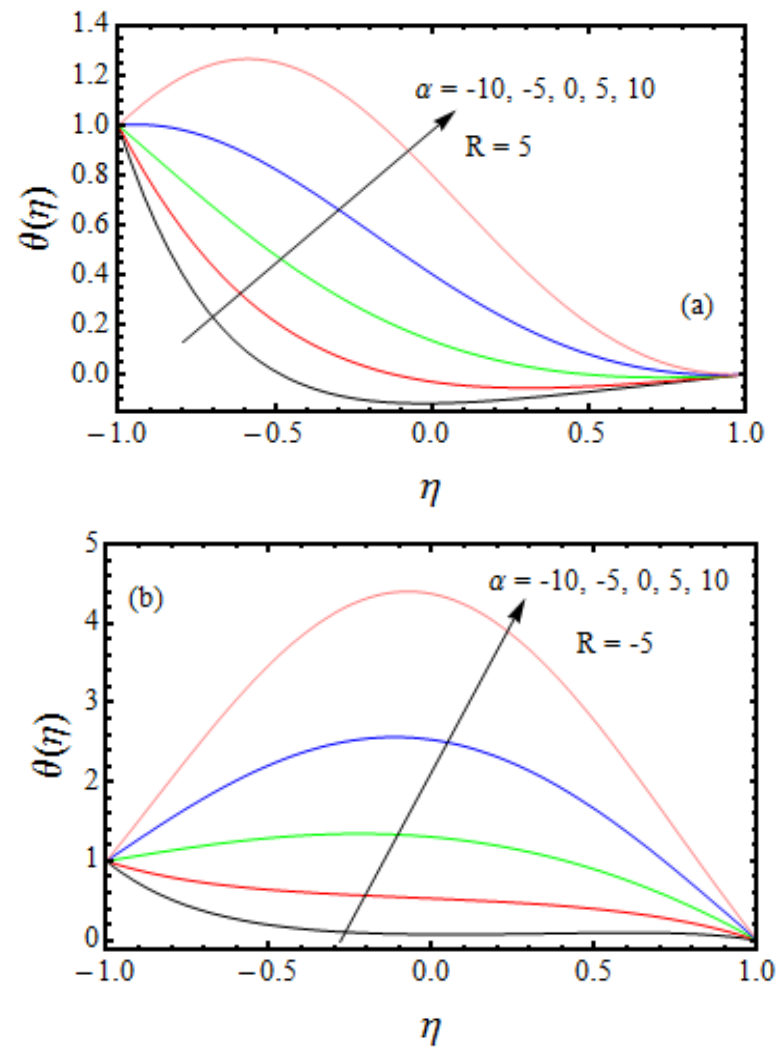

Fig. 9 Effect of $\alpha$ on temperature distribution for $\mathrm{Al}_{2} \mathrm{O}_{3}$ - water nanofluid.

The effect of the different nanoparticles $\left(\mathrm{Al}_{2} \mathrm{O}_{3}, \mathrm{Ag}, \mathrm{Cu}, \mathrm{TiO}_{2}\right)$ on axial velocity and temperature distribution on nanofluids for different base fluids such as water and Ethylene Glycol (EG) is shown in Fig. 11. From Fig. 11(a) it is observed that silver as nanoparticle leads to maximum axial velocity near the center of the channel as compared with $\mathrm{Al}_{2} \mathrm{O}_{3}, \mathrm{Cu}, \mathrm{TiO}_{2}$ for both the base fluids. From. Fig. 11(b) one can notice that the temperature of the nanofluid is higher for $\mathrm{Al}_{2} \mathrm{O}_{3}$ as nanoparticle on comparing with $\mathrm{Ag}, \mathrm{Cu}, \mathrm{TiO}_{2}$ for the both the base fluids.

Fig. 12 depicts the variation of $\theta$ for different values of $R d$. It is observed that, for the both cases wall suction combined with expansion and contraction, the temperature decreases for a given increase in $R d$ (see Fig. 12c, 12d) while it increases for the case of injection combined with contraction(see Fig. 12b). For the case of injection combined with wall expansion, for a given increase in $R d$, the temperature exhibits oscillating character and the maximum temperature is shifted to the walls(see Fig. 12a). 

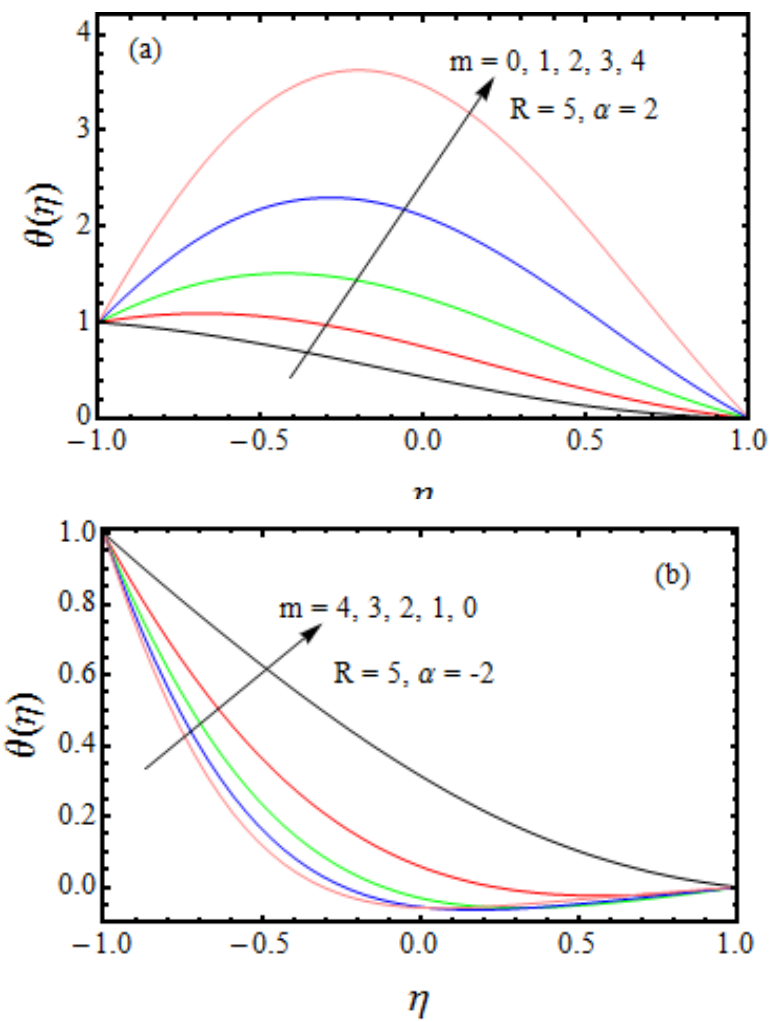

Fig. 10 Effect of $m_{1}$ on temperature distribution for $\mathrm{Al}_{2} \mathrm{O}_{3}$-water nanofluid.
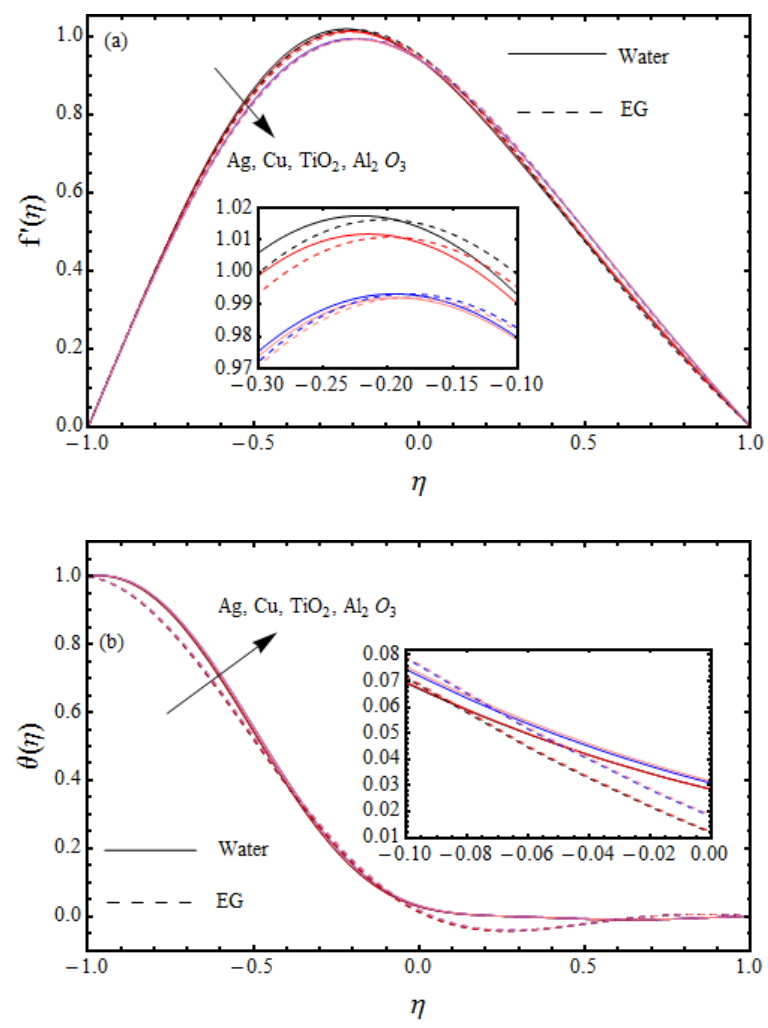

Fig. 11 Effect of different nanoparticles on (a) axial velocity (b) temperature for different base fluids water and Ethylene Glycol(EG) when $R=5, \alpha=2$
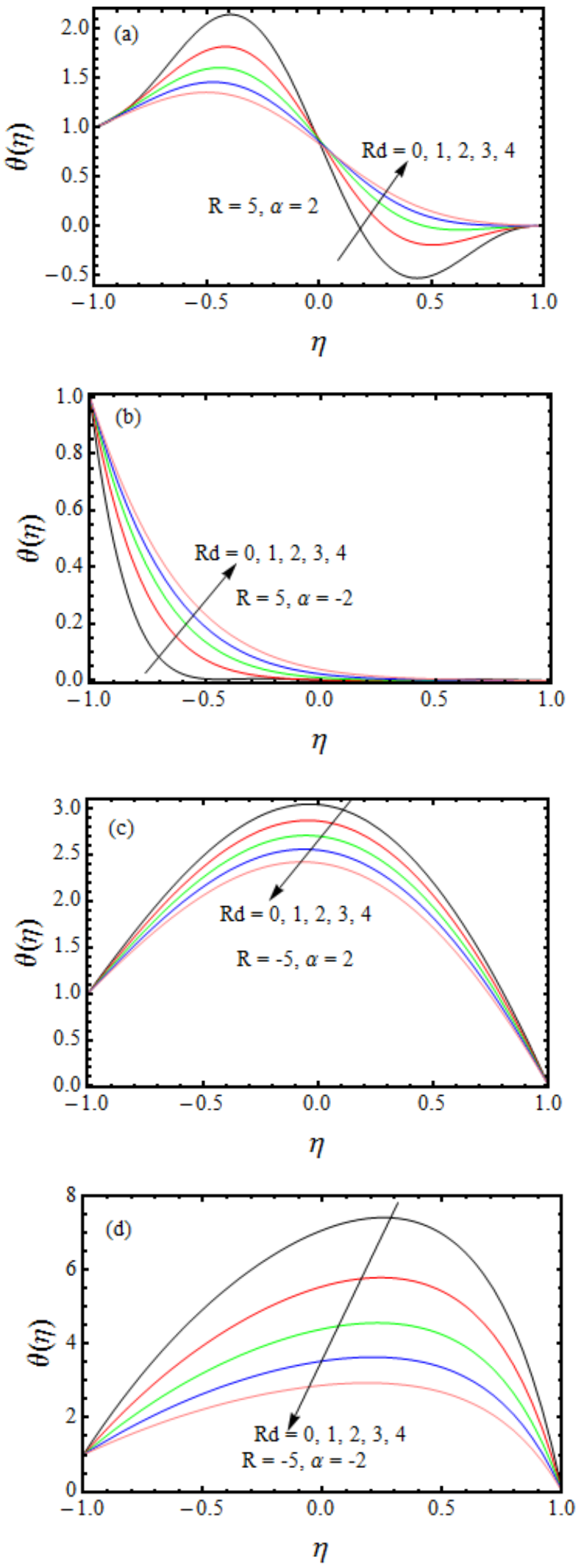

Fig. 12 Effect of $R d$ on temperature distribution for $\mathrm{Al}_{2} \mathrm{O}_{3}$-water nanofluid. 

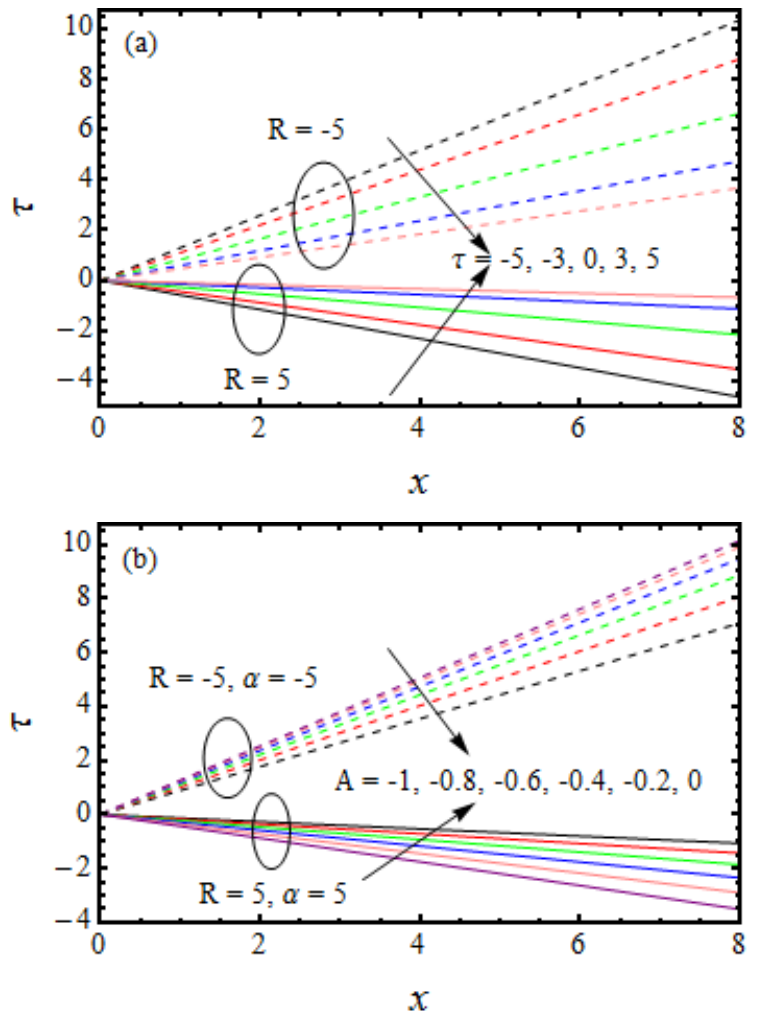

Fig. 13 Shear stress distribution for $\mathrm{Al}_{2} \mathrm{O}_{3}$-water nanofluid (a)effect of $\alpha$, (b) effect of $A$.
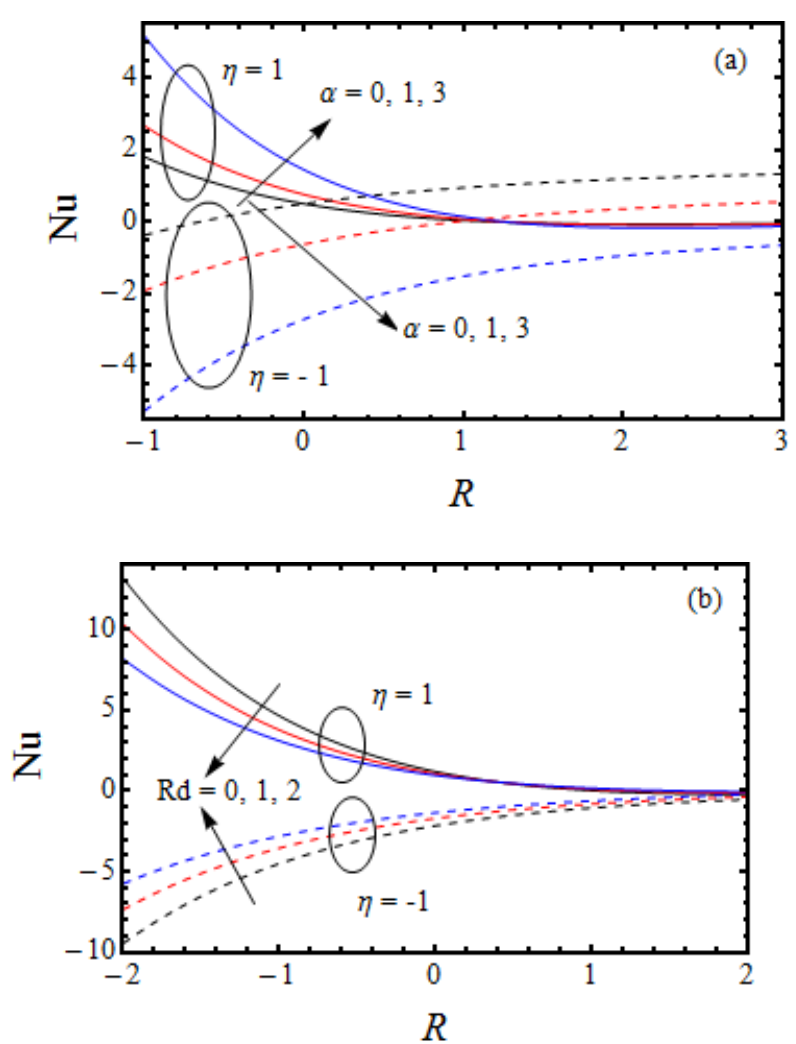

Fig. 14 Nusselt number distribution for $\mathrm{Al}_{2} \mathrm{O}_{3}$-water nanofluid (a)effect of $\alpha$, (b) effect of $R d$ when $\alpha=2$.
The influence of $\alpha$ and $A$ on shear stress distribution is shown in Fig. 13 for $\mathrm{Al}_{2} \mathrm{O}_{3}$-water nanofluid. From this figure it's clear that for every level of suction or injection the absolute shear stress along the wall surface is in proportion to $x$. From Fig. 13(a) one can observe that the absolute shear stress decreases as $\alpha$ increases for the case of expanding walls while it increases as $|\alpha|$ increases for the case of contracting walls. From Fig. 13(b), it can be seen that the absolute shear stress increases as the magnitude of $A$ increases for the both the cases of wall expansion combined with wall injection and wall contraction combined with wall suction. Fig. 14 shows the variation of heat transfer rate in terms of Nusselt number ( $N u$ ) against $R$ for different values of $\alpha$ and $R d$. From Fig. 14(a) it is noticed that $N u$ increases for a given increase in $\alpha$ at the upper wall while it decreases at the lower wall but the behavior is reversed for the variation of thermal radiation parameter (see Fig. 14(b)). The numerical values of heat transfer rate $-\phi_{2} \theta^{\prime}(-1)$ are presented in Tables 4 and 5 .

Table 4 Nusselt number distribution $\mathrm{Nu}$ for $\mathrm{Al}_{2} \mathrm{O}_{3}$-water nanofluid for different values of $\phi, m_{1}, R d$ when $\alpha=2, R=5, D a=0.5, A=-0.2, \operatorname{Pr}=6.2$.

\begin{tabular}{|c|c|c|c|}
\hline$\phi$ & $m_{1}$ & $R d$ & $-\phi_{2} \theta(-1)$ \\
\hline 0.00 & 1 & 1 & 0.113958 \\
\hline 0.02 & 1 & 1 & 0.128845 \\
\hline 0.04 & 1 & 1 & 0.144816 \\
\hline 0.06 & 1 & 1 & 0.161956 \\
\hline 0.06 & 0 & 1 & 0.576261 \\
\hline 0.06 & 1 & 1 & 0.669115 \\
\hline 0.06 & 2 & 1 & 0.725085 \\
\hline 0.06 & 3 & 1 & 0.753339 \\
\hline 0.06 & 1 & 0 & -0.018501 \\
\hline 0.06 & 1 & 1 & 0.161756 \\
\hline 0.06 & 1 & 2 & 0.296620 \\
\hline 0.06 & 1 & 3 & 0.397573 \\
\hline
\end{tabular}

Table 5a Variation of nanoparticle volume fraction $\phi$ on $-\phi_{2} \theta^{\prime}(-1)$ for $\alpha=2, R=5, D a=0.5, A=-0.2, \operatorname{Pr}=6.2, m_{1}=1$ for different nanoparticles with water as base fluid.

\begin{tabular}{|c|c|c|c|c|}
\hline \multirow{2}{*}{$\phi$} & \multicolumn{4}{|c|}{$R d=0$} \\
\cline { 2 - 5 } & $\mathrm{Al}_{2} \mathrm{O}_{3}$ & $\mathrm{Ag}$ & $\mathrm{Cu}$ & $\mathrm{TiO}_{2}$ \\
\hline 0.00 & -0.043264 & -0.043142 & -0.043142 & -0.043142 \\
\hline 0.02 & -0.036038 & -0.0259031 & -0.028761 & -0.036334 \\
\hline 0.04 & -0.027840 & -0.008340 & -0.013870 & -0.028869 \\
\hline 0.06 & -0.018576 & 0.009927 & 0.001776 & -0.020683 \\
\hline
\end{tabular}

Table 5b Variation of nanoparticle volume fraction $\phi$ on $-\phi_{2} \theta^{\prime}(-1)$ for $\alpha=2, R=5, D a=0.5, A=-0.2, \operatorname{Pr}=6.2, m_{1}=1$ for different nanoparticles with water as base fluid.

\begin{tabular}{|c|c|c|c|c|}
\hline \multirow{2}{*}{$\phi$} & \multicolumn{4}{|c|}{$R d=1$} \\
\cline { 2 - 5 } & $\mathrm{Al}_{2} \mathrm{O}_{3}$ & $\mathrm{Ag}$ & $\mathrm{Cu}$ & $\mathrm{TiO}_{2}$ \\
\hline 0.00 & 0.113958 & 0.113838 & 0.113838 & 0.113838 \\
\hline 0.02 & 0.128845 & 0.138920 & 0.135661 & 0.127326 \\
\hline 0.04 & 0.144816 & 0.164489 & 0.140624 & 0.141564 \\
\hline 0.06 & 0.161956 & 0.190907 & 0.152403 & 0.156610 \\
\hline
\end{tabular}

Table 4 depicts the numerical variations of $-\phi_{2} \theta^{\prime}(-1)$ for different values of $\phi, m_{1}, R d$ for $\mathrm{Al}_{2} \mathrm{O}_{3}$-water nanofluid. It is observed that heat 
transfer rate increases with an increase in $\phi, m_{1}$ while it decreases for a given increase in $R d$ (Zhang et al. 2015). Tables 5a and 5b show the influence of nanoparticle volume fraction $\phi$ on $-\phi_{2} \theta^{\prime}(-1)$ for different nanoparticles such as $\mathrm{Al}_{2} \mathrm{O}_{3}, \mathrm{Ag}, \mathrm{Cu}$ and $\mathrm{TiO}_{2}$ when water as base fluid and $R d=0,1$. It is clear that $-\phi_{2} \theta^{\prime}(-1)$ increases with increasing volume fraction of nanoparticles. From these tables it is noticed that silver nanoparticles lead to maximum heat transfer rate as compared with $\mathrm{Al}_{2} \mathrm{O}_{3}, \mathrm{Ag}, \mathrm{Cu}$, and $\mathrm{TiO}_{2}$ for water as base fluid. Further, it is observed that when $R d=0$, (in the absence of thermal radiation) as $\phi$ increases from $0 \%$ to $2 \%$ there is approximately $40 \%$, $33 \%, 17 \%$ and $16 \%$ increase in heat transfer rate for $\mathrm{Al}_{2} \mathrm{O}_{3}, \mathrm{Ag}$, $\mathrm{Cu}$, and $\mathrm{TiO}_{2}$ respectively, while there is $22 \%, 19 \%, 13 \%$ and $12 \%$ increase when $R d=1$.

\section{CONCLUSIONS}

In this study the flow and heat transfer characteristics of a nanofluid in an expanding or contacting porous channel with different permeability in the presence of thermal radiation are analyzed for different base fluids and nanoparticles. The considered problem has its potential applications in studies pertaining to binary gas diffusion, filtration, ablation cooling, surface sublimation and the regression of the burning surface in solid rocket motors, heating and cooling of channels, nuclear power plants, nuclear reactors, extraction of geothermal power, nanofluids in fuels, coolants in automotive, microchips cooling, nano drug delivery, cancer therapeutics.

Homotopy analysis method is employed to obtained analytical solutions for flow variables of the said problem. The convergence of the obtained series solutions is analyzed. The analytical solutions obtained through HAM are found to be in a good agreement with the numerical results. The effects of different parameters on flow variables have been discussed. The results of our analysis reveal that for $\mathrm{Al}_{2} \mathrm{O}_{3}$ water nanofluid the axial velocity is higher near the center of the channel for the case of expanding walls. The axial velocity profiles become symmetric as $A$ varies from 0 to -1 . It is also noticed that silver as nanoparticle leads to maximum axial velocity near the center of the channel as compared with $\mathrm{Cu}, \mathrm{TiO}_{2}$ and $\mathrm{Al}_{2} \mathrm{O}_{3}$ for the case of injection combined with wall contraction. Further, the temperature of nanofluid decreases with increasing injection for a constant $\alpha$ while it increases with an increase in $R d$ for the case of injection combined with wall contraction. The results demonstrate that the temperature of the nanofluid is maximum for $\mathrm{Al}_{2} \mathrm{O}_{3}$ on comparing with $\mathrm{Ag}, \mathrm{Cu}$ and $\mathrm{TiO}_{2}$ for both the base fluids in the case of wall expansion combined with injection. It is also observed that for the case of injection combined with wall contraction, the Nusslet number increases for a given increase in $\phi$ and $m_{1}$ while it decreases with an increase in $R d$. Furthermore, for the case of injection combined with wall contraction, when $R d=0$, as $\phi$ increases from $0 \%$ to $2 \%$ there is $40 \%$ (approximately) increase in heat transfer rate for silver nanoparticles, while there is $22 \%$ increase when $R d=1$. The results of Majdalani et al. (2002) for the base viscous fluid (in the absence of nanoparticles, porous medium and energy equation) can be captured from present analysis by taking $A=-1, R d=0, D a \rightarrow \infty$.

\section{ACKNOWLEDGEMENTS}

The author, S. Srinivas, gratefully acknowledges NBHM, Government of India for sanctioning a major research project under the grant number 2/48(19)/2012/ NBHM(R.P.)/R\&D II/9137. Further, A. Vijayalakshmi thankfully acknowledges NBHM for providing research fellowship.

\section{REFERENCES}

Abu-Nada, E., 2008, "Application of Nanofluids for Heat Transfer Enhancement of Separated Flows Encountered in a Backward Facing Step," International Journal of Heat and Fluid Flow, 29 (1), 242-249. http://dx.doi.org/10.1016/j.ijheatfluidflow.2007.07.001

Ahmadi, A.R., Zahmatkesh, A., Hatami, M., and Ganji, D.D., 2014 , "A Comprehensive Analysis of the Flow and Heat Transfer for a Nanofluid over an Unsteady Stretching Flat Plate," Powder Technology, 258, 125-133.

http://dx.doi.org/10.1016/j.powtec.2014.03.021

Bachok, N., Ishak, A., and Pop, I., 2012a, "Boundary Layer Flow Over a Moving Surface in a Nanofluid with Suction or Injection," Acta Mechanica Sinica, 28 (1), 34-40.

http://dx.doi.org/10.1007/s10409-012-0014-x

Bachok, N., Ishak, A., and Pop, I., 2012b, "The Boundary Layers of an Unsteady Stagnation-Point Flow in a Nanofluid," International Journal of Heat and Mass Transfer, 55 (23-24), 6499-6505.

http://dx.doi.org/10.1016/j.ijheatmasstransfer.2012.06.050

Boutros, Y.Z., Abd-el-Malek, M.B., Badran, N.A., and Hassan, H.S., 2007, "Lie-Group Method Solution for Two-Dimensional Viscous Flow between Slowly Expanding or Contracting Walls with Weak Permeability," Applied Mathematical Modelling, 31, 1092-1108. http://dx.doi.org/10.1016/j.apm.2006.03.026

Brewster, M.Q., 1992, "Thermal Radiative Transfer and Properties," John Wiley \& Sons. Inc., New York.

Choi, S.U.S., 1995, "Enhancing Thermal Conductivity of Fluids with Nanoparticle, Developments and Applications of Non-Newtonian Flows," ASME FED, 231, 99-105.

Dauenhauer, E.C., and Majdalani, J., 1999, "Unsteady Flows in SemiInfinite Expanding Channels with Wall Injection," AIAA paper, 993523 .

Dinarvand, S., Rashidi, M.M., and Doosthoseini, A., 2009, “Analytical Approximation Solutions for Two-Dimensional Viscous Flow through Expanding or Contracting Gaps with Permeable Walls," Central Europian Journal of Physics, 7(4), 791-799. http://dx.doi.org/10.2478/s11534-009-0024-x

Dogonchi, A.S., Hatami, M., and Domairry, G., 2015, "Motion Analysis of a Spherical Solid Particle in Plane Couette Newtonian Fluid Flow," Powder Technology, 274, 186-192.

http://dx.doi.org/10.1016/i.powtec.2015.01.018

Domairry, G., and Hatami, M., 2014, "Squeezing Cu-Water Nanofluid Flow Analysis between Parallel Plates by DTM-Padé Method," Journal of Molecular Liquids, 193, 37-44.

http://dx.doi.org/10.1016/j.molliq.2013.12.034

Fakour, M., Vahabzadeh, A., Ganji, D.D., and Hatami, M., 2015, "Analytical Study of Micropolar Fluid Flow and Heat Transfer in a Channel with Permeable Walls," Journal of Molecular Liquids, 204, 198-204.

http://dx.doi.org/10.1016/j.molliq.2015.01.040

Ghasemi, S.E., Hatami, M., Sarokolaie, A.K., and Ganji, D.D., 2015, "Study on Blood Flow Containing Nanoparticles through Porous Arteries in Presence of Magnetic Field using Analytical Methods," Physica E, 70, 146-156.

http://dx.doi.org/10.1016/j.physe.2015.03.002 
Hady, F.M., Ibrahim, F.S., Abdel-Gaied, S.M., and Eid, M.R., 2012, "Radiation Effect on Viscous Flow of a Nanofluid and Heat Transfer over a Nonlinearly Stretching Sheet," Nanoscale Research Letters, 7, 229.

http://dx.doi.org/10.1186/1556-276X-7-229

Hamad, M.A.A., Pop, I., and Md Ismail, A.I., 2011, "Magnetic Field Effects on Free Convection Flow of a Nanofluid Past a Vertical SemiInfinite Flat Plate," Nonlinear Analysis: Real World Applications, 12, 1338-1346.

http://dx.doi.org/10.1016/j.nonrwa.2010.09.014

Haq, U.R., Nadeem, S., Akbar, N.S., and Khan, Z.H., 2015, "Buoyancy and Radiation Effect on Stagnation Point Flow of Micropolar Nanofluid along a Vertically Convective Stretching Surface," IEEE Transactions on Nanotechnology, 14 (1), 42-50.

http://dx.doi.org/10.1109/TNANO.2014.2363684

Hatami, M., and Ganji, D.D., 2014, "Natural Convection of Sodium Alginate(SA) Non-Newtonian Nanofluid Flow between Two Vertical Flat Plate by Analytical and Numerical Methods," Case Studies in Thermal Engineering, 2, 14-22.

http://dx.doi.org/10.1016/j.csite.2013.11.001

Hatami, M., Nouri, R., and Ganji, D.D., 2013, "Forced Convection Analysis for MHD $\mathrm{Al}_{2} \mathrm{O}_{3}$-Water Nanofluid Flow over a Horizontal Plate," Journal of Molecular Liquids, 187, 294-301. http://dx.doi.org/10.1016/j.molliq.2013.08.008

Hatami, M., Sheikholeslami, M., and Ganji, D.D., 2014, "Nanofluid Flow and Heat Transfer in an Asymmetric Porous Channel with Expanding or Contracting Wall," Journal of Molecular Liquids, 195, 230-239.

http://dx.doi.org/10.1016/j.molliq.2014.02.024

Hayat, T., Gull, N., Farooq, M., and Ahmad, B., 2015a, "Thermal Radiation Effect in MHD Flow of Powell-Eyring Nanofluid Induced by a Stretching Cylinder," Journal Aerospace Engineering, 29(1), 04015011-1-10.

http://dx.doi.org/10.1061/(ASCE)AS.1943-5525.0000501

Hayat, T., Imtiaz, M., Alsaedi, A., and Kutbi, M.A., 2015b, "MHD Three-Dimensional flow of Nanofluid with Velocity Slip and Nonlinear Thermal Radiation," Journal of Magnetism and Magnetic Materials, 396, 31-37.

http://dx.doi.org/10.1016/j.jmmm.2015.07.091

Hayat, T., Sajjad, R., Abbas, Z., Sajid, M., and Hendi, A.A., 2011 , "Radiation Effects on MHD Flow of Maxwell Fluid in a Channel with Porous Medium," International Journal of Heat and Mass Transfer, 54 (4), 854-862.

http://dx.doi.org/10.1016/j.ijheatmasstransfer.2010.09.069

Khanafer, K., Vafai, K., and Lightstone, M., 2003, "Buoyancy-Driven Heat Transfer Enhancement in a Two-Dimensional Enclosure Utilizing Nanofluids," International Journal of Heat Mass Transfer, 46(19), 3639-3653.

http://dx.doi.org/10.1016/S0017-9310(03)00156-X

Kim, J., Kang, Y.T., and Choi, C.K., 2004, "Analysis of Convective Instability and Heat Transfer Characteristics of Nanofluids," Physics of Fluids, 16 (7), 2395-2401.

http://dx.doi.org/10.1063/1.1739247

Liao, S.J., 2003, "Beyond Perturbation: Introduction to Homotopy Analysis Method," Boca Raton: CRC Press, Chapman and Hall.
Liao, S.J., 2014, "Advances in the Homotopy Analysis Method," World Scientific.

Madhesh, D., and Kalaiselvam, S., 2014, "Experimental Study on the Heat Transfer and Flow Properties of $A g$-Ethylene Glycol Nanofluid as a Coolant," Heat and Mass Transfer, 50 (11), 1597-1607. http://dx.doi.org/10.1007/s00231-014-1370-9

Mahian, O., Mahmud, S., and Heris, S.Z., 2012, "Analysis of Entropy Generation between Co-Rotating Cylinders using Nanofluids," Energy, 44 (1), 438-446.

http://dx.doi.org/10.1016/j.energy.2012.06.009

Majdalani, J., Zhou, C., and Dawson, C.A., 2002, "Two-Dimensional Viscous Flow between Slowly Expanding or Contracting Walls with Weak Permeability," Journal of Biomechanics, 35 (10), 1399-1403. http://dx.doi.org/10.1016/S0021-9290(02)00186-0

Majdalani, J., and Zhou, C., 2003, "Moderate-to-Large Injection and Suction Driven Channel Flows with Expanding or Contracting Walls," Journal of Applied Mathematics and Mechanics, 83 (3), pp. 181-196. http://dx.doi.org/10.1002/zamm.200310018

Malvandi, A., and Ganji, D.D., 2014, "Magnetic Field on Nanoparticles Migration and Heat Transfer of Water/Alumina Nanofluid in a Channel," Journal of Magnetism and Magnetic Materials, 362, 172179.

http://dx.doi.org/10.1016/j.jmmm.2014.03.014

Nadeem. S., and Ul-Haq, R., 2015, "MHD Boundary Layer Flow of a Nanofluid Passed through a Porous Shrinking Sheet with Thermal Radiation," Journal of Aerospace Engineering, 28 (2), 04014061. http://dx.doi.org/10.1061/(ASCE)AS.1943-5525.0000299

Oztop, H.F., and Abu-Nada, E., 2008, "Numerical Study of Natural Convection in Partially Heated Rectangular Enclosures Filled with Nanofluids," International Journal of Heat and Fluid Flow, 29, 13261336.

http://dx.doi.org/10.1016/j.ijheatfluidflow.2008.04.009

Paul, D., and Mandal, G., 2014, "Influence of Thermal Radiation on Mixed Convection Heat and Mass Transfer Stagnation-Point Flow in Nanofluids over Stretching/Shrinking Sheet in a Porous Medium with Chemical Reaction," Nuclear Engineering and Design, 273, 644-652. http://dx.doi.org/10.1016/j.nucengdes.2014.01.032

Rad, P.M., and Aghanajafi, C., 2009, "The Effect of Thermal Radiation on Nanofluid Cooled Microchannels," Journal of Fusion Energy, 28, 91-100.

http://dx.doi.org/10.1007/s10894-008-9153-2

Rahimi-Gorji, M., Pourmehran, O., Hatami, M., and Ganji, D.D., 2015, "Statistical Optimization of Microchannel Heat Sink (MCHS) Geometry Cooled by Different Nanofluids using RSM Analysis," The European Physical Journal Plus, 130, 22.

http://dx.doi.org/10.1140/epip/i2015-15022-8

Rahman, M.M., and Eltayeb, I.A., 2013, "Radiative Heat Transfer in a Hydromagnetic Nanofluid Past a Non-Linear Stretching Surface with Convective Boundary Condition," Meccanica, 48 (3), 601-615. http://dx.doi.org/10.1007/s11012-012-9618-2

Reddy, A.S., Srinivas, S., and Ramamohan, T.R., 2013, “Analysis of Heat and Chemical Reaction on an Asymmetric Laminar Flow between Slowly Expanding or Contracting Walls," Heat Transfer-Asian Research, 42 (5), 422-443.

http://dx.doi.org/10.1002/htj.21036 
Sheikholeslami, M., Ganji, D.D., Javed, M.Y., and Ellahi, R., 2015, "Effect of Thermal Radiation on Magnetohydrodynamics Nanofluid Flow and Heat Transfer by Means of Two Phase Model," Journal of Magnetism and Magnetic Materials, 374, 36-43.

http://dx.doi.org/10.1016/j.jmmm.2014.08.021

Sheikhzadeh, G.A., Dastmalchi, M., and Khorasanizadeh, H., 2013, "Effects of Walls Temperature Variation on Double Diffusive Natural Convection of $\mathrm{Al}_{2} \mathrm{O}_{3}$-Water Nanofluid in an Enclosure," Heat and Mass Transfer, 49, 1689-1700. http://dx.doi.org/10.1007/s00231-013-1209-9

Si, X., Xin-hui, S., Zheng, L., Lin, P., Zhang, X., and Zhang, Y., 2011a, "Homotopy Analysis Solution for Micropolar Fluid Flow through Porous Channel with Expanding or Contracting Walls of Different Permeabilities," Applied Mathematics and Mechanics, 32(7), 859-874. http://dx.doi.org/10.1007/s10483-011-1465-6

Si, X., Zheng, L., Xinxin, Z., and Jianhong, Y., 2011b, "Homotopy Analysis Method for the Heat Transfer in a Asymmetric Porous Channel with an Expanding or Contracting Wall," Applied Mathematical Modelling, 35, 4321-4329.

http://dx.doi.org/10.1016/j.apm.2011.03.009

Srinivas, S., Shukla, A.K., Ramamohan, T.R., and Reddy, A.S., 2015, "Influence of Thermal Radiation on Unsteady Flow over an Expanding or Contracting Cylinder with Thermal-Diffusion and Diffusion-Thermo Effects," Journal of Aerospace Engineering, 28, 04014134-10. http://dx.doi.org/10.1061/(ASCE)AS.1943-5525.0000470

Srinivas, S., Subramanyam Reddy, A., and Ramamohan, T.R., 2012, "A study on Thermal-Diffusion and Diffusion-Thermo Effects in a Two-Dimensional Viscous Flow between Slowly Expanding or Contracting Walls with Weak Permeability," International Journal of Heat and Mass Transfer, 55 (11-12), 3008-3020.

http://dx.doi.org/10.1016/j.ijheatmasstransfer.2012.01.050
Srinivas, S., Vijayalakshmi, A., Ramamohan, T.R., and Subramanyam Reddy, A., 2014, "Hydromagnetic Flow of a Nanofluid in a Porous Channel with Expanding or Contracting Walls," Journal of Porous Media, 17 (11), 953-967.

http://dx.doi.org/10.1615/JPorMedia.v17.i11.20

Uchida, S., and Aoki, H., 1977, "Unsteady Flows in a Semi-Infinite Contracting or Expanding Pipe," Journal of Fluid Mechanics, 82 (2), 371-387. http://dx.doi.org/10.1017/S0022112077000718

Vajravelu, K., Prasad, K.V., Lee, J., Lee, C., Pop, I., and Van Gorder, R.A., 2011, "Convective Heat Transfer in the Flow of Viscous $\mathrm{Ag}$ Water and $C u$-Water Nanofluids over a Stretching Surface," International Journal of Thermal Sciences, 50 (5), 843-851. http://dx.doi.org/10.1016/j.ijthermalsci.2011.01.008

Xin-Hui, S., Zheng, L., Zhang, X., and Chao, Y., 2011, "Homotopy Analysis Solutions for the Asymmetric Laminar Flow in a Porous Channel with Expanding or Contracting Walls," Acta Mechanica Sinica, 27 (2), 208-214. http://dx.doi.org/10.1007/s10409-011-0430-3

Zhang, C., Zheng, L., Zhang, X., and Chen, G., 2015, "MHD Flow and Radiation Heat Transfer of Nanofluids in Porous Media with Variable Surface Heat Flux and Chemical Reaction," Applied Mathematical Modelling, 39 (1), 165-181.

http://dx.doi.org/10.1016/j.apm.2014.05.023

Zheng, L., Zhang, C., Zhang, X., and Zhang, J., 2013, "Flow and Radiation Heat Transfer of a Nanofluid over a Stretching Sheet with Velocity Slip and Temperature Jump in Porous Medium," Journal of the Franklin Institute, 350 (5), 990-1007. http://dx.doi.org/10.1016/j.jfranklin.2013.01.022 